\title{
Sonocatalysis: A Potential Sustainable Pathway for the Valorization of Lignocellulosic Biomass and Derivatives
}

\author{
Ewelina Kuna' ${ }^{1}$ Ronan Behling ${ }^{2} \cdot$ Sabine Valange ${ }^{2} \cdot$ \\ Gregory Chatel $^{3} \cdot$ Juan Carlos Colmenares ${ }^{1}$
}

Received: 21 November 2016/Accepted: 18 February 2017/Published online: 23 March 2017

(C) The Author(s) 2017. This article is an open access publication

\begin{abstract}
Lignocellulosic biomass represents a natural renewable chemical feedstock that can be used to produce high value-added chemicals and platform molecules. Nowadays, there are extensive studies on a variety of aspects concerning the valorization of lignocellulosic biomass into desirable products. Among the current technologies for biomass conversion some require extreme conditions along with high temperatures and pressures. Therefore, major technological innovations based on more economical and environmental methodologies are currently developed both in academic laboratories and in industry. In this context, ultrasound-assisted catalysis constitutes an alternative method offering new strategies to upgrade biomass. The possibility of combining catalysis with sonication indeed provides avenues that are worth exploring for the valorization of lignocellulosic compounds into value-added chemical feedstocks. In this mini-review, the available sonochemical systems are first presented, with a focus on the most important ultrasonic parameters, which is intended to provide a mechanistic background. Next, this contribution aims to provide insight into the most recent developments along with prominent examples in the field of sonocatalysis applied to the chemical transformation of lignocellulosic biomass and its derivatives.
\end{abstract}

Chapter 1 was originally published as Kuna, E., Behling, R., Valange, S., Chatel, G. \& Colmenares, J. C. Top Curr Chem (Z) (2017) 375: 41. DOI 10.1007/s41061-017-0122-y.

Gregory Chatel

gregory.chatel@univ-smb.fr

$\bowtie$ Juan Carlos Colmenares

jcarloscolmenares@ichf.edu.pl

1 Institute of Physical Chemistry, Polish Academy of Sciences, Kasprzaka 44/52, 01-224 Warsaw, Poland

2 Institut de Chimie des Milieux et Matériaux de Poitiers (IC2MP), Université de Poitiers, CNRS, ENSIP, B1, 1 rue Marcel Doré, 86073 Poitiers Cedex 9, France

3 Univ. Savoie Mont Blanc, LCME, F-73000 Chambéry, France 


\section{Graphical Abstract}

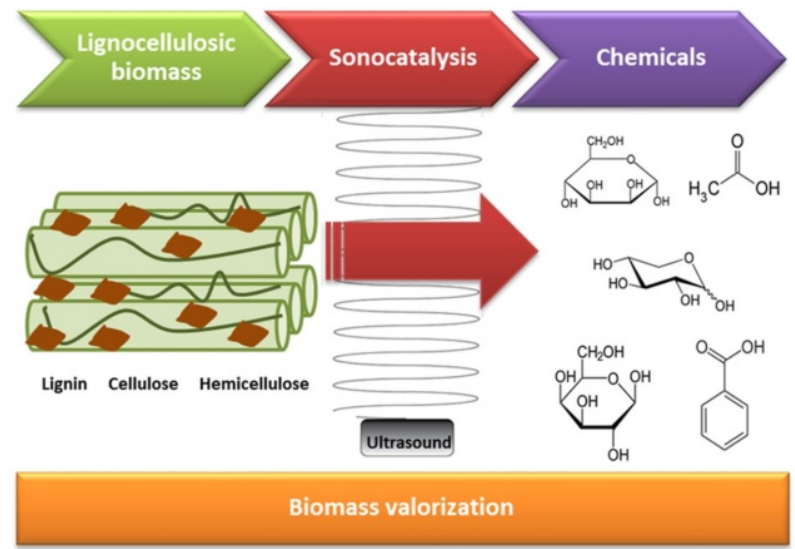

Keywords Sonochemistry - Sonocatalysis - Biomass upgrading · Lignocellulosic waste valorization $\cdot$ Lignocellulose depolymerization

\section{Introduction}

The worldwide accessibility of biomass undoubtedly plays a fundamental role in sustainable energy production. In favorable circumstances, around $25 \%$ of global energy requirements can be supplied by biomass [1]. The enormous potential of plant materials resides in the presence of lignocellulosic residues coming from forest residues, energy crops, municipal and industrial wastes [2]. This type of renewable resource is now increasingly used for the production of value-added chemicals and transport fuels [3]. Nevertheless, plant dry matter possesses a sturdy structure, which complicates the effective conversion process of lignocellulosic biomass into platform chemicals. Lignocellulose is a recalcitrant biopolymer composed of the semi-crystalline polysaccharide cellulose, the polysaccharide hemicellulose, and the three-dimensional amorphous phenylpropanoid lignin polymer $[4,5]$. The conversion of lignocellulosic feedstock leads to the production of a variety of added value platform chemicals, including phenolic compounds ( $p$ coumaryl alcohol, coniferyl alcohol, and sinapyl alcohol), aliphatic acids (formic acid, acetic acid, levulinic acid), and furan aldehydes (hydroxymethyl furfural) [6]. It is worth mentioning that the accessibility to desired products is dependent on biomass pretreatment methods, which have a significant influence on the production of their derived feedstocks for further valorization strategies. Notwithstanding, the selection of the most favorable pretreatment process depends predominantly on the target molecule and many other factors such as economical and environmental aspects [7]. The depolymerization process of lignocellulosic biomass includes physical, chemical, and biological treatments, as well as various combinations thereof (Fig. 1) [7-9]. The physical pretreatment of biomass as a first step for 


\section{Lignocellulosic biomass pretreatment}

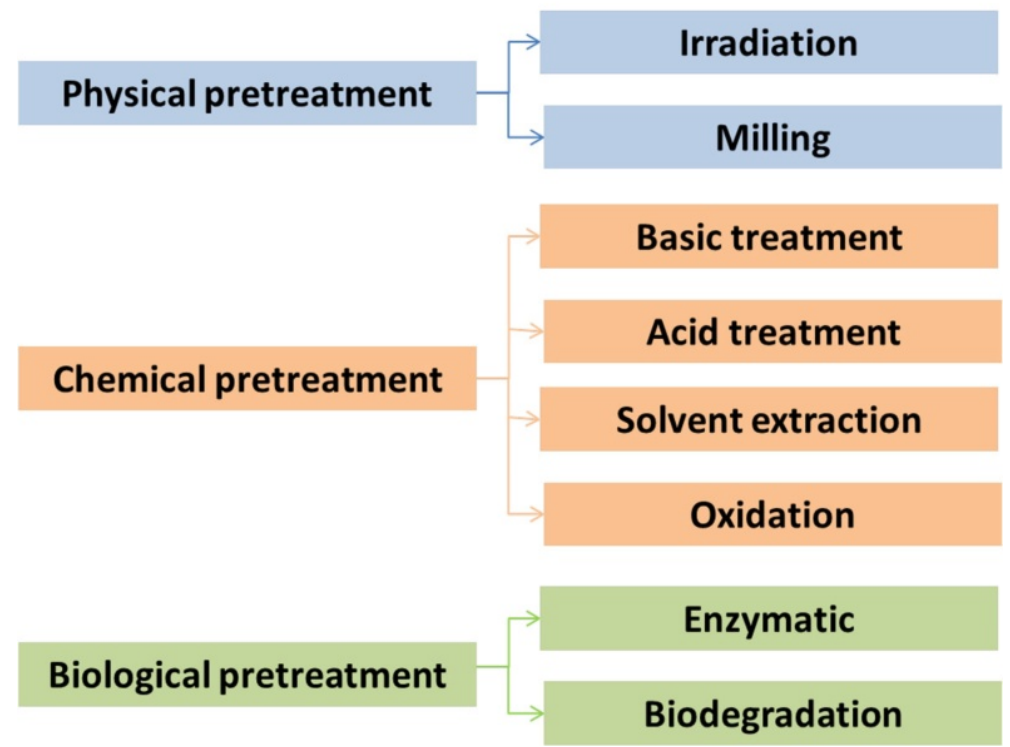

Fig. 1 Methods for pretreatment of lignocellulosic biomass. (Adapted and modified from Ref. [9])

further upgrading is achieved by mechanical comminution of lignocellulosic materials through a combination of chipping, grinding, or milling. In the particular case of cellulosic biomass, such physical process leads to a size reduction due to a decrease of both the degree of polymerization and the crystallinity, resulting in the increase of the mass transfer and the improvement of the hydrolyzation reaction. However, the energy consumption required for physical treatment is higher than the theoretical energy content available in lignocellulose, which makes it prohibitively expensive for large-scale uses [10]. An alternative for deconstructing lignocellulosic biomass is chemical pretreatment. This method is based on catalytic processes such as acid/alkaline hydrolysis, oxidative delignification, cracking, reduction reaction, among others [11]. Acid pretreatment allows converting hemicellulose into monomeric sugars (e.g. glucose, xylose) and soluble oligomers, whereas alkaline hydrolysis renders lignin recoverable. Delignification of lignocellulosic biomass can also be performed by treating in the presence of oxidizing agents (e.g. hydrogen peroxide, ozone, and oxygen) [12]. In most of these cases, catalysis increases the efficiency of the process and is responsible for the major effects achieved by pretreatment [13]. The application of catalysts provides a more effective approach in biological processing, where the yield of hydrolysis is relatively low along with long pretreatment times. Enzymatic hydrolysis can also be improved by combining ultrasonic pretreatment with the organosolv process. Ultrasound has the potential to enhance the separation and hydrolysis of lignocellulosic materials [12]. By contrast, 
the combined use of organic solvents (including ionic liquids) or their mixtures with water was shown to enhance dissolution of biomass and increase depolymerization rates [14].

The immensity of available pretreatment methods creates opportunity to choose those which enable downstream processing of lignocellulosic biomass. Recovered carbohydrate polymers such as cellulose and hemicellulose can further be transformed into fermentable sugars and then into fuels or feedstock chemicals. Valuable products can also be obtained from lignin through development and integration of current and new technologies such as sonocatalysis, heterogeneous photocatalysis, or microwave-assisted conversion [15, 16]. According to a classification proposed in previous papers [8, 17] a simplified summary of conversion strategies is given in Fig. 2. Thermal technologies can be used to produce solid feedstocks (e.g. biochar), liquids (e.g. oils and viscous tars), and gaseous products. However, methods such as pyrolysis and gasification require large energy inputs due to the high processing temperatures. Chemical conversion techniques (e.g. catalyzed depolymerization, hydrotreating, oxidation, liquid-phase reforming) constitute a more energy efficient and environmentally sustainable way to valorize biomass [17].

In the present review, we focus on the recent literature advances on sonocatalytic valorization of lignocellulosic biomass and their platform molecules. It is evident that catalysis is regarded as a key route enabling technology for pretreatment and conversion of lignocellulosic biomass [8]. Over the past few years, research on the development and optimization of highly active and selective catalytic systems has been an ongoing activity to overcome drawbacks associated with harsh chemical conditions, low yield production, and high processing cost [18]. Additionally,

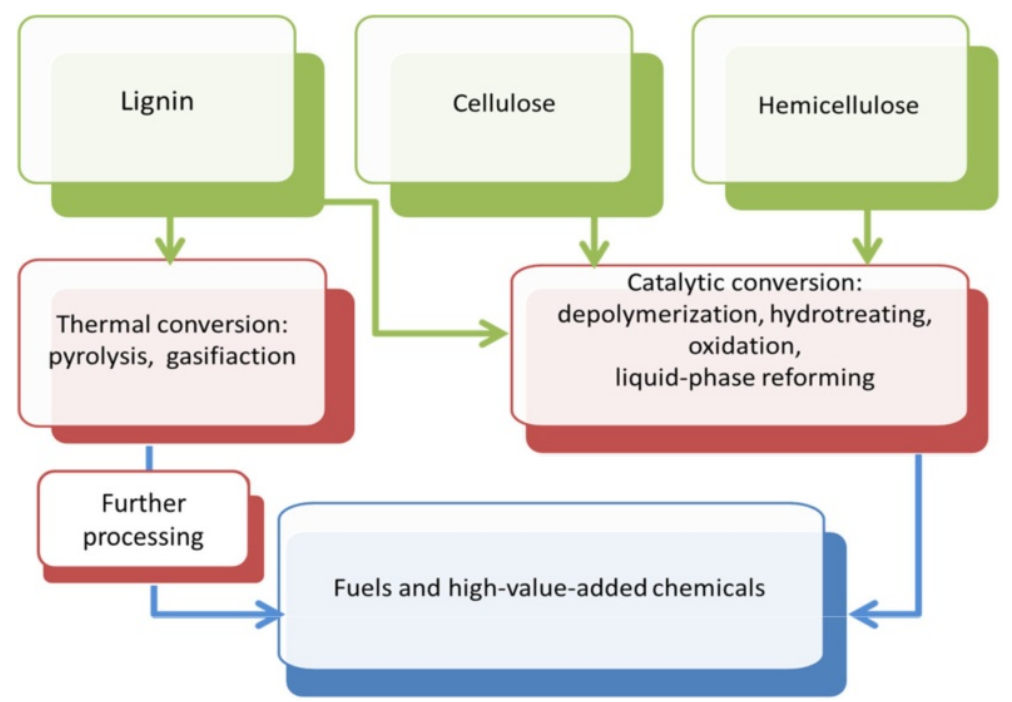

Fig. 2 Biorefinery strategies for lignocellulosic biomass valorization to fuels and chemicals. (Adapted and modified from Refs. [8, 17]) 
sonochemical-assisted reactions offer opportunities to develop environmentally friendly and cost-effective processes for biomass upgrading [4, 19].

\section{Generalities on Sonochemistry}

Sonochemical effects arise from cavitation, which is defined as the phenomenon of formation, growth, and implosive collapse of bubbles under the influence of an ultrasonic field in liquids [20,21]. Cavitation can be categorized into various forms (acoustic, hydrodynamic, optic, and particle cavitation) depending on the method of generation and associated ultrasonic/experimental parameters (frequency, acoustic power, shape of the reactor, solvents, temperature, pressure, etc.). Acoustic and hydrodynamic cavitation may generate physical and chemical changes in solution in contrast to optic and particle cavitations. Numerous "hot spots" can be created by acoustic and hydrodynamic cavitation due to the accumulation of a huge amount of energy which in turn results in immense pressures and temperatures [22, 23]. The pressure fluctuation induced by changing the geometry of the flow system produces hydrodynamic cavitation, while the pressure fluctuation in the passageway of sound waves induced acoustic cavitation [24].

Acoustic cavitation takes place within collapsing bubbles (gas-phase chemistry), on the outer side of the bubbles (solution-phase chemistry) and at the liquid-solid interface (physical modification) [21]. The chemical and physical effects of ultrasound eventuate from the cavitation phenomenon and not from direct interaction between chemical species and ultrasonic waves [21, 25]. The chemical effect of ultrasound is the consequence of the implosive collapse of microbubbles, producing free-radicals, whereas the physical effects are the result of shock waves

\section{Liquid}

\section{Acoustic pressure}

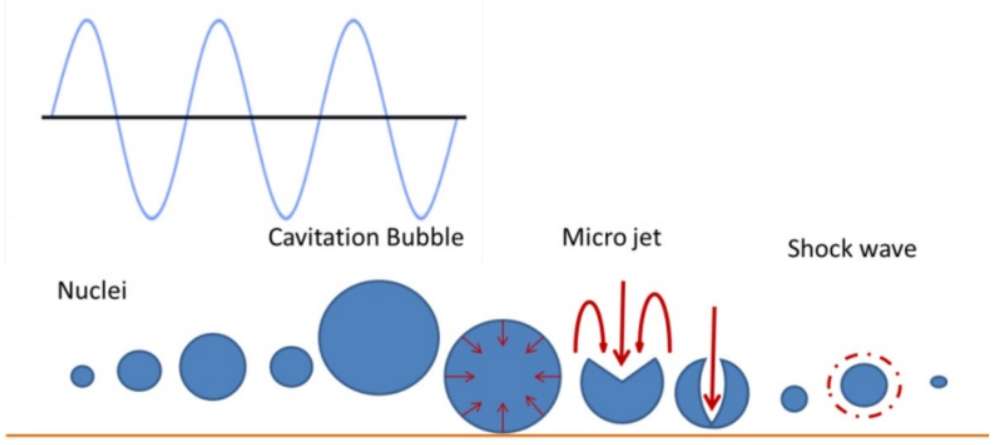

Solid Surface

Fig. 3 Acoustic cavitation mechanism 
and microjet generated during symmetric and asymmetric cavitation, respectively (Fig. 3) [26].

The rate of motion of ultrasound is significantly greater than the molecular scale [23]. Generally, when the sound velocities in a liquid are around 1000-1500 $\mathrm{m} \mathrm{s}^{-1}$ the power ultrasound (in opposition to diagnostic ultrasound, particularly used in medical imaging) can oscillate from approximately 10 to $10^{-4} \mathrm{~cm}$ over the frequency range of $20-2000 \mathrm{kHz}[21,22]$. The compression and expansion waves put the liquid under dynamic tensile stress. As a result, the local pressure decreases adequately below the saturated vapor pressure and initiate cavitation [21, 27]. Microbubbles present in a liquid absorb energy from ultrasound waves and undergo a rapid overgrowth leading to violent collapse. The final stage of implosion is almost adiabatic and provides extreme conditions [21, 28].

\subsection{Homogeneous and Heterogeneous Sonochemical Systems}

Sonochemical reactions can be classified into three categories, namely homogeneous sonochemistry of liquids, heterogeneous sonochemistry of liquid-liquid or liquid-solid systems, and sonocatalysis (which involves the aforementioned systems) (Fig. 4) [29, 30]. Homogeneous systems include radical reactions, which are accelerated by sonication and that follow via radical or radical-ion intermediates [32]. In this case, the chemical bonds are broken under the high temperature and pressure generated during cavitation [24]. The short-lived chemical species are turned back to the bulk liquid and react with other species [32]. Sometimes homogeneous sonochemistry followed by secondary reactions taking place in the liquid, especially in the case of compounds of low volatility, which can interact with

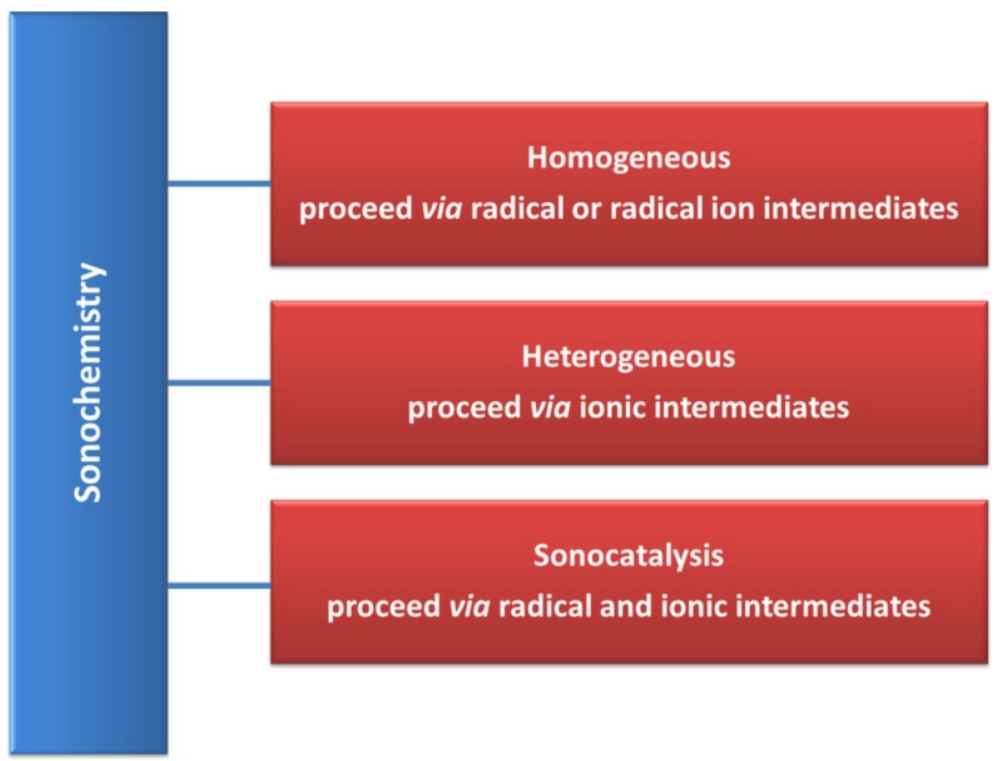

Fig. 4 Classification of sonochemistry reactions 
radical species produced from solvent sonolysis [33]. In homogeneous systems, where the surroundings are uniform, the cavity remains spherical. Cavity collapse in heterogeneous system may proceed via two fundamentally different mechanisms such as microjet impact and shock wave damage. Deformation in the cavity is caused by asymmetric motions of the molecules in liquid during cavity collapse. The expanded bubble's potential energy is converted into kinetic energy of a highspeed liquid jet that passes through the bubble's interior and pierces the opposite bubble wall. The available energy is predominantly handed over to the accelerating jet rather than the bubble wall itself $[34,35]$. High energy concentration can cause an intense damage to the boundary surface. The stress fracture on the surface can be invoked by shockwaves generated through cavity collapse in the liquid. The impingement of microjets and shockwaves form the localized erosion, which is in charge of ultrasonic cleaning and another sonochemical effects such as particle size reduction or improved mass transfer on heterogeneous reactions [24]. In heterogeneous systems, the use of ultrasound accelerates chemical reactions, drawing on mechanical effects of cavitation. The dynamics of the cavity collapse changes dramatically when cavitation takes place in a liquid nearby a solid surface [32]. The imposition of the heterogeneous and homogeneous sonochemistry includes a radical and an ionic reaction mechanism. Indeed, depending of the ultrasonic frequency (see Sect. 2.2), the sonication enhances radical formation and mechanical effects (e.g. mass transfer) [30].

\subsection{More Important Parameters in Sonochemistry}

The selection of ultrasonic parameters (such as frequency, acoustic power, temperature, pressure, solvent, design of reactors, etc.) is a crucial issue in order to optimize the system and thus influence efficiency of a chemical process. There are different ways to optimize these parameters depending on the target experimental outcome; they can be chosen by taking into account the data concerning studies on bubble cavitation characteristics [36]. The problem connected with cavitation distribution and quantification might be addressed by using different experimental or theoretical mapping techniques [37]. The basic aspects of each method, their applicability, pros and cons have been highlighted by Sutkar and Gogate [37, 38]. Their analysis allows one to determine the behaviour of cavitational activity regarding reactor geometry over a range of operating parameters [24]. In order to estimate mutual relation, bubble dynamics analysis has been also employed by other researchers [37, 39]. The study includes quantifying the correlation between the pressure and temperature linked with cavity implosion as a function of intensity, frequency, and initial radius of the nuclei [24].

The cavity dynamics is defined by two elements: the maximum magnitude accomplished by the cavity before implosion (that determines the pressure and temperature generating during collapse) and the lifetime of the cavity (that defines the distance travelled by the cavity from the place where it is formed) [37, 40]. Both elements are of paramount importance for the design of sonochemical reactors and should be optimized by appropriately adjusting the various geometric and operating parameters [37]. The reactor design has significant effects on the cavitational 
activity, in terms of the reactor and horn tip diameters (including the ratio of both diameters) and the position of the horn tip immersed in the liquid [24, 41].

Another factor that has an influence on the cavitation is the amount of energy, which is supplied to the bulk solution. The power dissipation rate varies on the extent of temperature growth, which causes direct changes in the gas solubility and vapour pressure, generating active cavitation sites. Energy efficiency is expressed by the amount of energy dissipated into the liquid and is generally calculated by a calorimetric method (monitoring the temperature as a function of time allows to estimate the acoustic power) [24, 37].

The effect on the bubble cavitation is directly connected to the frequency of the ultrasound. We can distinguish frequencies at low range $(20-80 \mathrm{kHz})$ and high range $(>150 \mathrm{kHz})$ [42]. High frequency does not promote the occurrence of active cavitation, because of insufficient duration of the ultrasonic cycle, which is required for the growth, radial motion, and collapse of bubbles. The short-lived bubble can boost the concentration of free radicals and may have a higher probability to get out the cavitation site to the bulk mixture. Compared to lower frequency ultrasound, high ultrasonic frequencies produce less violent cavitation and lead to chemical effects. Low frequencies are responsible for physical effects, where rapid cavitation leading to enormous temperatures and pressures at the cavitation site [43]. It is noteworthy that physical properties of the liquid phase have also many effects on ultrasonic cavitation. Relative low volatility, viscosity, and high surface tension of liquid solvents are preferred for favoring efficient cavitation [37]. Active cavitation occurs also in heterogeneous sites in liquids such as impurities, gas microbubbles, non-volatile additives, etc. [36].

The physical and chemical effects produced by ultrasonic cavitation in a liquid phase provide extreme local conditions such as immense local heating $\left(\sim 5000{ }^{\circ} \mathrm{C}\right)$, pressures $(\sim 1000 \mathrm{~atm})$, and heating/cooling rates $\left(10^{10 \circ} \mathrm{C} \mathrm{s}^{-1}\right)$ [34]. Microjet streams and shock waves created by cavitation promote better energy and mass transfer, which has an impact on accelerating chemical reaction, increasing conversion, improving the yield, and enhancing the selectivity in both homogeneous and heterogeneous systems [44]. For this reason, sonochemistry has found wide applications in chemical synthesis used for the preparation of nanostructured materials (e.g. hybrid lignocellulosic materials) [45] and modification of inorganic materials (e.g. clay minerals) [46]. Additionally, the benefits of the use of ultrasound in organic synthesis are also highlighted by interesting review articles [47-49]. Some key examples where synthetically useful sonochemical organic transformations carried out in homogenous and heterogeneous conditions include: hydrolysis [50], cycloaddition (e.g. Diels-Alder reaction) [51], coupling (e.g. Suzuki reaction, Mitsunobu reaction) [47], isomerization (e.g. glucose to fructose) [52], alkylation [53], esterification [54], and polymerization reactions [55]. 


\section{Ultrasound-Assisted Catalysis for Lignocellulosic Biomass Valorization}

\subsection{Principles of Sonocatalysis}

The combination of sonochemistry with catalysis can be used to accomplish a number of chemical reactions with convenient workup conditions (e.g. shorter reaction times) in contrast to more conventional methods [56]. Heterogeneous reactions follow via ionic intermediates provoked by mechanical effects, whereas radical reaction enhanced mainly by sonication. In the case when radical and ionic mechanisms lead to other products, ultrasound might promote the radical reaction, which can also provide new synthetic pathways [30]. The fundamental rule of sonocatalysis is diffusion and sorption of the main components on a solid surface followed by a series of heterogeneous chemical reactions on active sites [57]. In a heterogeneous reaction system, the improvement of chemical reaction is mainly caused by physical effects. The physical phenomena improve mass transfer from turbulent mixing and acoustic streaming, generate cavitation erosion at liquid-solid interfaces, and are responsible for deformation of solid surfaces (Fig. 5) [25].

The effect of ultrasonic irradiation on a heterogeneous catalyst may cause physical and chemical modifications (e.g. changes in crystallization, dispersion, and surface properties, as well as changes on catalytic reactivity during reaction (Fig. 5) [58]. The chemical rate increases due to enhancement of external transport phenomena and the increase in temperature at the catalyst surface. Acoustic

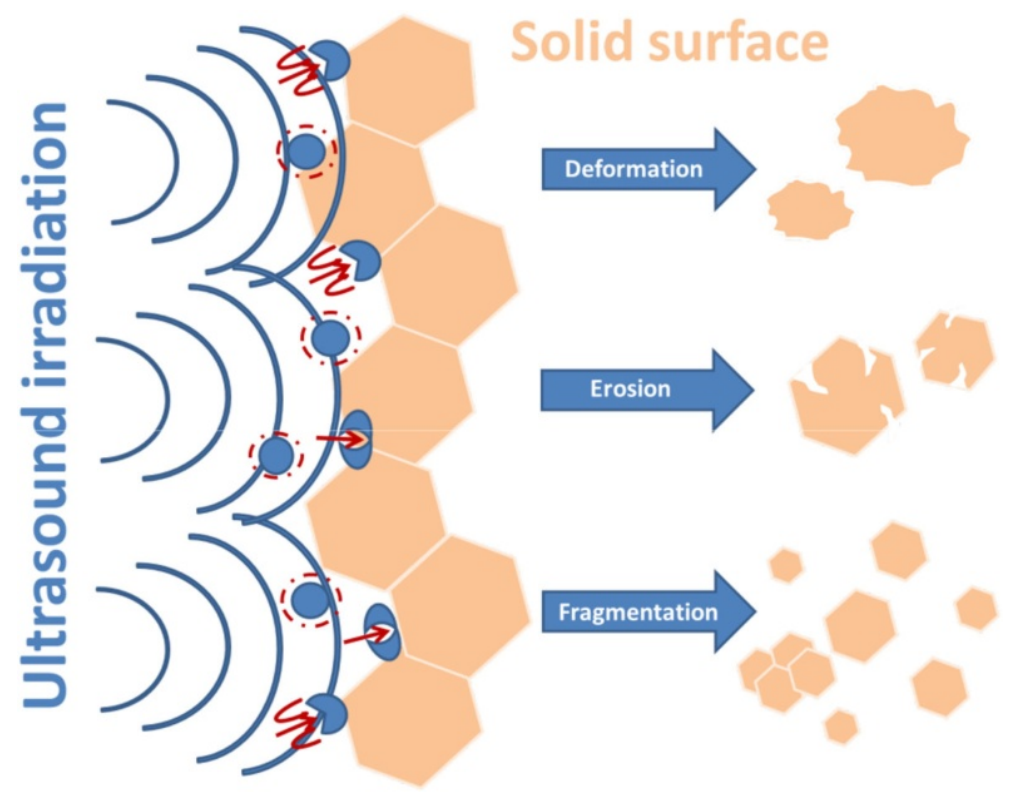

Fig. 5 Effect of ultrasound irradiation on a heterogeneous catalyst surface 
cavitation can induce the breaking of the catalytic particle and gives more accessibility to the internal surface for the reagents. In the gas-liquid-solid system (e.g. hydrogenation reactions) sonication increases the interphase surface and favors the removal of outer oxide or other passivating layers from the catalyst surface [49].

\subsection{Homogenous and Heterogeneous Sonocatalysis}

The application of ultrasound in homogeneous and heterogeneous reaction systems in the presence of catalysts is viewed as a convenient technique for lignocellulosic valorization. Catalysis assisted by ultrasound includes a variety of reactions such as hydrolysis, hydrogenation, oxidation [59]. Sonication improves hydrolysis of lignocellulosic materials into sugars and their subsequent fermentation into bioethanol. The main reason for enhanced conversion is the substantial improvement of mass transfer in reacting systems, as well as the activation of chemical and biological catalysts [37]. Yunus et al. reported that the acid hydrolysis of palm oil to xylose was increased from 22 to $52 \%$ under ultrasound pretreatment $(20 \mathrm{kHz}$, $2 \mathrm{~kW}$ ), in comparison to silent conditions (Table 1; Entry 1) [60]. An improvement of the reaction rate under ultrasound $(25 \mathrm{kHz}, 600 \mathrm{~W})$ was noticed also by Choi and Kim during the acid-catalyzed hydrolysis of starch (Table 1; Entry 2) [61]. Ultrasonic energy can have a direct influence on hydrolysis and fermentation reactions of cellulosic materials, while the application of ultrasound with enzymes accelerates saccharification and the fermentation rate [36]. Cavitation effects enhance the transport of enzyme macromolecules to the surface of the substrate, whereas the substrate surface is opening up to the action of enzymes due to the mechanical effect of cavitation [4, 62]. Additionally, the sono-assisted enzymatic conversion of cellulose performed in solvents such as ionic liquids (ILs) yielded high performances by promoting high conversion, yield, and selectivity [36]. The combination of ultrasound with ILs has indeed recently attracted much interest for lignocellulosic biomass valorization [36]. For example, enzymatic hydrolysis of lignocellulose assisted by ultrasound $(45 \mathrm{kHz}, 100 \mathrm{~W})$ in imidazolium-based ionic liquid media improves cellulosic conversion from 75 to $95 \%$ [63] and saccharification ratio to $92 \%$ from $55 \%$ [64] in $60 \mathrm{~min}(24 \mathrm{kHz}, 35 \mathrm{~W})$. The benefits of ultrasound-assisted enzymatic processes are the enhanced solvation and the increased reactivity of biomass reactants, coupled to reactions taking place at lower temperature within shorter time and with less requirement for acid or base catalysts [36].

The nature of solvents fulfils a crucial role in the lignocellulose depolymerization process. In some cases, ionic liquids were used only selectively to dissolve lignin rather than hemicellulose or cellulose [65]. For example, the catalytic hydroprocessing of lignin under ultrasound conditions resulted in a higher efficiency when conducted in an ionic liquid (1-butyl-3-methylimidazolium acetate) in comparison to organic solvents and water. Considerable enhancement in conversion up to $90 \%$ was noticed with nano-Ni and $\mathrm{NiO}$ nanosheets catalysts [66]. The conversion rate and the mass distribution of products depends on the procedure used for the pretreatment (acidic or alkali) of lignin. This means that in most cases, acidic extraction leads to a larger extent of depolymerization reaction (Table 1; Entry 3) 


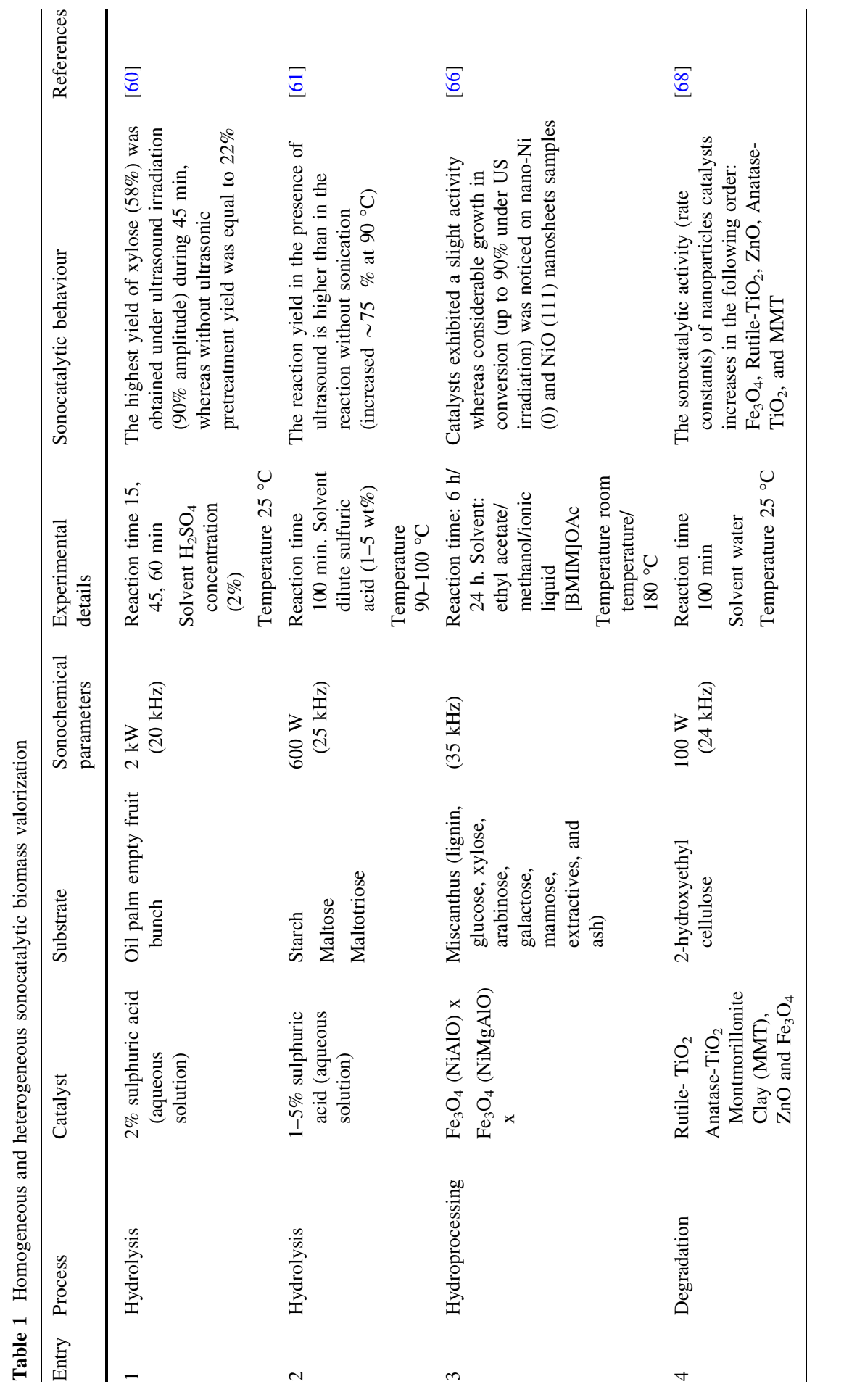




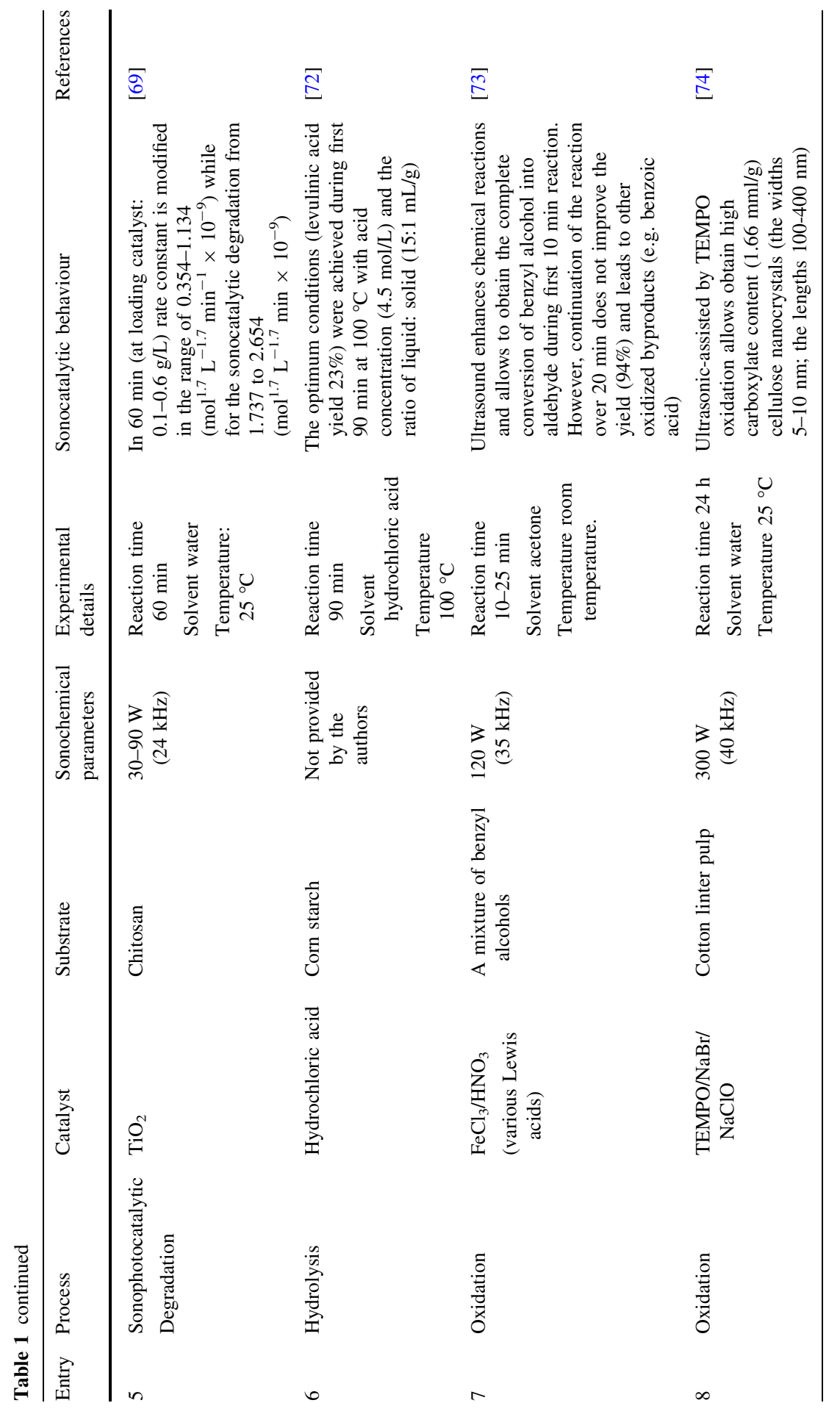




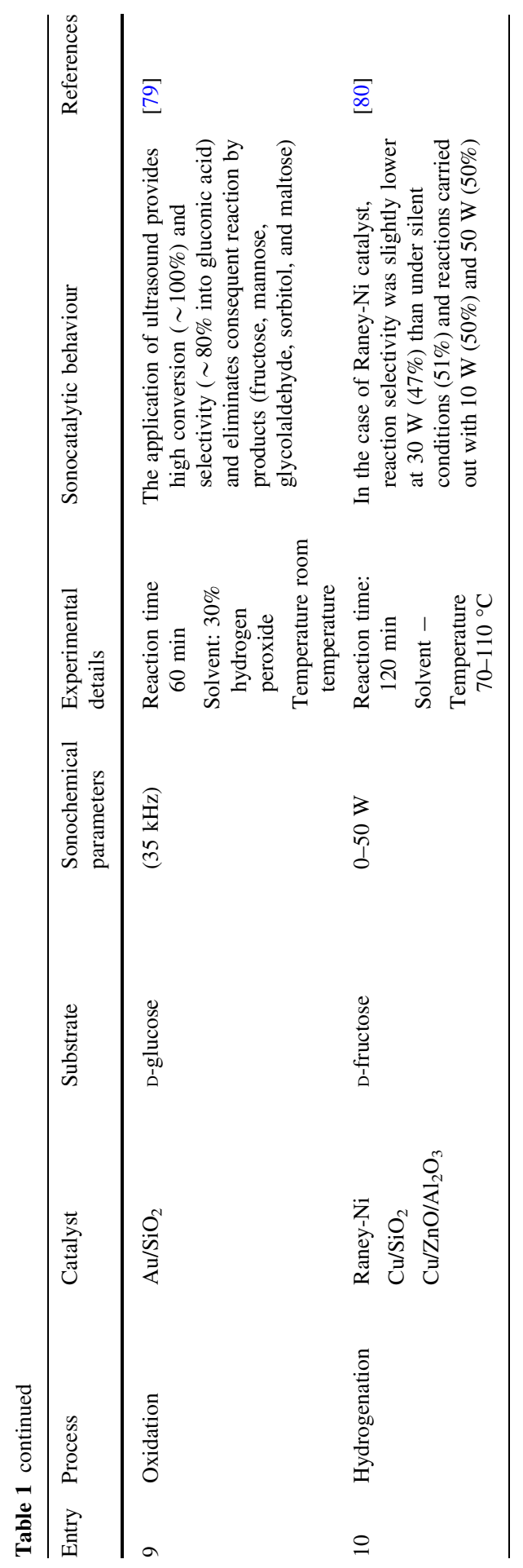


[66]. Additionally, work by Napoly and co-workers shows that it is possible to obtain vanillin-based monomers with yield equal to $0.51 \mathrm{wt} \%$ in the presence of a tungsten-based catalyst and an oxidizing agent such as $\mathrm{H}_{2} \mathrm{O}_{2}$ [67]. $\mathrm{Na}_{2} \mathrm{WO}_{4}$ acted as the most promising catalyst, which promoted an effective system, where ultrasound generated sufficient oxidation conditions $(20 \mathrm{kHz}, 11 \mathrm{~W})$ and involved strengthened oxidative coupling of phenoxy radicals [67].

A relevant study about the degradation of cellulose was recently published by Taghizadeh (Table 1; Entry 4) [68]. The degradation behaviour of 2-hydroxyethyl cellulose was conducted in the presence of a variety of heterogeneous catalysts (such as titanium oxide, montmorillonite clay, zinc oxide, and iron oxide) under ultrasound irradiation $(24 \mathrm{kHz})$. Sonolytic degradation (without catalyst) increases with increasing of ultrasonic power (in the range of 30-90 W); however, it is remarkably lower in comparison to the efficiency of the sonocatalytic degradation. The results obtained revealed that the combined use of catalysts and US irradiation improved the degree of cellulose depolymerization. Among all the catalysts tested, the most efficient was $\mathrm{Fe}_{3} \mathrm{O}_{4}$, which provided a better ability for radical generation through electron transfer between the metal ion and the water molecules during the sonication process. The possibility of combining ultrasound irradiation with heterogeneous photocatalysis was also studied by the same research group (Table 1; Entry 5) [69]. The complete degradation of chitosan (with cellulose-based structure) was achieved during $1 \mathrm{~h}$ in the presence of titanium oxide at $24 \mathrm{kHz}$. In this case, sonophotocatalysis enhanced the production of reactive radicals as well as increasing the active sites of the catalyst surface.

Behling et al. recently investigated the low frequency $(20 \mathrm{kHz})$ ultrasoundassisted aqueous-phase oxidation of vanillyl alcohol to vanillin using a heterogeneous $\mathrm{Co}_{3} \mathrm{O}_{4}$ catalyst with hydrogen peroxide as the primary oxidizing agent under mild reaction conditions (low temperature and atmospheric pressure). The outcome of this work was that the ultrasound-assisted catalytic reaction is faster $(4 \mathrm{x})$, more selective $(2.3 \mathrm{x})$, and more efficient $(2.7 \mathrm{x})$ than the corresponding reaction carried out under silent conditions [70]. Additionally, a large decrease of the overall energy consumption was observed under ultrasound (36 vs. $288 \mathrm{~kJ}$ ). Moreover, from an environmental point of view, green metrics indicators such as the E factor and the process mass intensity (PMI) calculated for both activation systems clearly showed the benefit of the ultrasound-mediated reaction [70]. The ultrasound-microwave assisted process is also an interesting approach for lignocellulosic biomass valorization. The simultaneous microwave $(100 \mathrm{~W})$ and ultrasound irradiations was shown to improve the hydrolysis reaction rates of glucose [71] and corn starch [72] (Table 1; Entry 6) in $60 \mathrm{~min}$. In both cases, the reaction yield to levulinic acid was high (49 and $23 \%$ from glucose and corn starch, respectively) in comparison with those reported in the open literature.

Kardos and Luche [42] have investigated interesting approaches to obtain high value-added chemicals through the conversion of biomass feedstocks such as polymeric carbohydrates to lower weight molecules. In the case of polysaccharides, the partial or total depolymerization has to be taken into account. Hydrolytic procedures, already mentioned before, have been widely examined to accomplish this aim. Nevertheless, particular attention should be paid to oxidation reactions. For 
example, glucose being selectively oxidized into glucuronic acid in the presence of iron sulfate under ultrasound irradiation $(100 \mathrm{kHz})$, whereas hexoses are oxidized to the corresponding uronic acids. It is interesting to note that this type of reaction cannot be performed without oxygen or acoustic activation [42].

The sonocatalytic oxidation of primary benzyl alcohols into the corresponding aldehydes was reported by Naik et al. [73]. They noted that the mixture of $\mathrm{HNO}_{3}$ / $\mathrm{FeCl}_{3}$ provides high yields (80-94\%) of aldehydes within 10-25 min (Table 1; Entry 7). Reactions carried out under silent conditions showed fourfold lower rates and yields than those performed under sonication. The application of ultrasound $(35 \mathrm{kHz}, 120 \mathrm{~W})$ gave excellent yields with short reaction times and allowed to avoid over-oxidized products.

The work of Qin et al. [74] showed that the TEMPO/ $\mathrm{NaBr} / \mathrm{NaOCl}$ oxidation system assisted by ultrasound $(40 \mathrm{kHz}, 300 \mathrm{~W})$ can be used to prepare cellulose nanocrystals with high carboxylate content from cotton linter pulp (Table 1; Entry 8). This is consistent with the study carried out by Brochette-Lemoine et al. [75]. The results of these investigations indicated that the rate of the oxidation of methyl $\alpha$-D-glucopyranoside or sucrose was increased in the presence of ultrasound. Moreover, the reaction can then occur without the commonly used sodium bromide owing to the ability of ultrasound to generate the active oxidizing species during the catalytic cycle. Additionally, sonication accelerated the oxidation reaction, especially when the frequency of ultrasound was increased from 20 up to $500 \mathrm{kHz}$ [76]. In order to scale up the oxidation of cellulose, Paquin et al. [77] proposed the use of a continuous flow-through system instead of the classical standard batch mode. The flow-through reactor increased the reaction rate $(\sim 36 \%)$ in comparison to the batch reactor while decreasing the overall energy consumption $(\sim 87 \%)$ [4].

Another reaction worth interest for the industry is the production of gluconic acid from D-glucose. Rinsant et al. [78] have described a way to selectively oxidize glucose via a sono-Fenton process with hydrogen peroxide in the presence of iron (II) sulfate as catalyst. In contrast to preconceived ideas, they proved that sonochemistry does not constitute an "intensive energy consuming" technology. Furthermore, the energy consumption could be minimized when ultrasound-based processes are optimized. Energy consumption (under ultrasound) was lower than that attained under conventional reactions. Remarkably high conversion $(\sim 100 \%)$ and selectivity $(\sim 95 \%)$ values were obtained only after $15 \mathrm{~min}(20 \mathrm{kHz}$, $\left.0.25 \mathrm{~W} \mathrm{~mL}^{-1}\right)$. This example on D-glucose oxidation relies on the efficient combination of an eco-friendly oxidant (hydrogen peroxide) and ultrasound, which constitutes a promising strategy for the valorization of biomass. In the same strategy of sugar oxidation by sonocatalysis, Bujak et al. [79] observed that silica-supported gold catalysts are extremely active and selective for D-glucose oxidation to gluconic acid at ambient temperature and under ultrasound conditions $(35 \mathrm{kHz})$ (Table 1 ; Entry 9). The application of ultrasound is of crucial importance to provide not only high conversion of glucose into gluconic acid with $100 \%$ yield, but also high reproducibility.

The effect of sonication $\left(26,78\right.$ and $\left.130 \mathrm{~W} \mathrm{~cm}^{-2}\right)$ on D-fructose hydrogenation in the presence of heterogeneous catalysts was examined by Toukoniitty et al. [80]. The reaction rate and selectivity were investigated at various conditions of 
temperature $\left(70-110^{\circ} \mathrm{C}\right)$, pressure $(10,30$, and 50 bar), and ultrasonic power $(0-50 \mathrm{~W})$ (Table 1; Entry 10). The application of sonication during the hydrogenation reaction considerably accelerated the reaction rate in the presence of the $\mathrm{Cu} / \mathrm{SiO}_{2}$ catalyst. High temperature and pressure had a moderate effect on the catalyst activity whereas the variation of nominal ultrasonic power input effectively improved the reaction rates.

\section{Challenges and Future Perspectives}

In most cases, combining catalysis with sonication has interesting effects on reactions course. In the present mini-review, we have shown that the use of sonocatalysis allows avoiding harsh chemical conditions, along with reducing reaction times and improving heat and mass transfer, thereby increasing chemical rate constants, yields, and selectivities. Hence, the ultrasound-assisted catalysis can be successfully applied for the pretreatment and chemical conversion of lignocellulosic biomass and its derivatives in a variety of processes such as hydrolysis, oxidation, and hydrogenation reactions. The recent studies on the use of ultrasound to assist catalytic reactions have clearly shown great advantages and technological potential of this concept for the chemical industry, especially when thinking about processes under flow. More significant scientific breakthroughs for biomass valorization are expected to occur in this innovative field in the near future. Last, but not least, and continuing in the same lines, the important role of ultrasound on photocatalysis (ultrasound and photocatalysis together) for the valorization of lignocellulosic biomass and its derivatives might be also a promising research avenue worth broad interest in the huge spectrum of possibilities offered by lignocellulose-based processes, for instance, sonophotocatalytic proof concepts for: lignocellulosic biomass depolymerization [81], biohydrogen [82], and biomethane production [83].

Acknowledgements Prof. Dr. Colmenares would like to thank the National Science Centre (Poland) for the support within the project Sonata Bis Nr. 2015/18/E/ST5/00306 and the support from COST Action FP1306 for networking and possibilities for meetings and future students exchange. M.Sc. Kuna would like to acknowledge the COST Association (Action FP1306) for the Trainee Grant (COST-STSMECOST-STSM-FP1306-010216-068720). Ronan Behling acknowledges the CAPES Foundation (Brazilian Ministry of Education) for awarding his PhD scholarship (13342-13-4) through the Science without Borders program.

Open Access This article is distributed under the terms of the Creative Commons Attribution 4.0 International License (http://creativecommons.org/licenses/by/4.0/), which permits unrestricted use, distribution, and reproduction in any medium, provided you give appropriate credit to the original author(s) and the source, provide a link to the Creative Commons license, and indicate if changes were made.

\section{References}

1. Perlack RD, Wright LL, Turhollow AF, Graham RL, Strokes BJ, Erbach DC (2015) Biomass as feedstock for a bioenergy and bioproducts industry: The technical feasibility of a billion-ton annual 
supply. https://www1.eere.energy.gov/bioenergy/pdfs/final_billionton_vision_report2.pdf. Accessed April 2015

2. United Nations Environmental Programme Division of Technology, Industry and economics International Environmental Technology Centre Osaka/Shiga J. Converting Waste Agricultural Biomass into a Resource. United Nations Environ. Program. (2009) Japan http://www.unep.org/ietc/Portals/ 136/Publications/Waste\%20Management/WasteAgriculturalBiomassEST_Compendium.pdf.

Accesed July 2009

3. Briens C, Piskorz J, Berruti F (2008) Biomass valorization for fuel and chemicals production. A review. Int J Chem React Eng 6:1542-6580

4. Chatel G, De Oliveira Vigier K, Jérôme F (2014) Sonochemistry: what potential for conversion of lignocellulosic biomass into platform chemicals? Chemsuschem 7:2774-2787

5. Mora-Pale M, Meli L, Doherty TV, Linhardt RJ, Dordick JS (2011) Room temperature ionic liquids as emerging solvents for the pretreatment of lignocellulosic biomass. Biotechnol Bioeng 6:1229-1245

6. Jönsson LJ, Alriksson B, Nilvebrant NO (2013) Bioconversion of lignocellulose: inhibitors and detoxification. Biotechnol Biofuels 6:16-26

7. Harmsen P, Huijgen W (2010) Literature review of physical and chemical pretreatment processes for lignocellulosic Biomass. Energy. ECN-E-10-013:1-49. https://www.ecn.nl/docs/library/report/2010/ e10013.pdf. Accessed September 2010

8. Zakzeski J, Bruijnincx PC, Jongerius AL, Weckhuysen BM (2010) The catalytic valorization of lignin for the production of renewable chemicals. Chem Rev 110:3552-3599

9. Silveira MHL, Morais ARC, Lopes AM, Olekszyszen DN, Bogel-Łukasik R, Andreaus R, Ramos LP (2015) Current pretreatment technologies for the development of cellulosic ethanol and biorefineries. Chemsuschem 8:3366-3390

10. Kumar P, Barrett DM, Delwiche MJ, Stroeve P (2010) Methods for pretreatment of lignocellulosic biomass for efficient hydrolysis and biofuel production. Ind Eng Chem Anal Ed 48:3713-3729

11. Brodeur G, Yau E, Badal K, Collier J, Ramachandran KB, Ramakrishnan S (2011) Chemical and physicochemical pretreatment of lignocellulosic biomass: a review. Enzyme Res 787532:1-17

12. Bussemaker MJ, Zhang D (2011) Effect of ultrasound on lignocellulosic biomass as a pretreatment for biorefinery and biofuel applications. Ind Eng Chem Res 52:3563-3580

13. Nitsos CK, Mihailof CM, Matis KA, Lappas AA, Triantafyllidis KS (2013) The role of catalytic pretreatment in biomass valorization toward fuels and chemicals. In: Triantafyllidis KS, Lappas AA, Stöcker M (eds) The role of catalysis for the sustainable production of bio-fuels and bio-chemicals, 1st edn. Elsevier, Amsterdam, pp 217-260

14. Akhtar N, Gupta K, Goyal D, Goyal A (2015) Recent advances in pretreatment technologies for efficient hydrolysis of lignocellulosic biomass. Environ Prog Sustain Energy 35:489-511

15. Gallezot P (2012) Conversion of biomass to selected chemical products. Chem Soc Rev 44:60-72

16. Li SH, Liu S, Colmenares JC, Xu YJ (2016) A sustainable approach for lignin valorization by heterogeneous photocatalysis. Green Chem 18:594-607

17. Li C, Zhao X, Wang A, Huber GW, Zhang T (2015) Catalytic Transformation of Lignin for the Production of Chemicals and Fuels. Chem Rev 115:11559-11624

18. Subhedar PB, Gogate PR (2016) Ultrasound assisted intensification of biodiesel production using enzymatic interesterification. Ultrason Sonochem 29:67-75

19. Amaniampong PN, Karam A, Trinh QT, Xu K, Hirao H, Jérôme F, Chatel G (2017) Selective and Catalyst-free Oxidation of D-Glucose to D-Glucuronic acid induced by High-Frequency Ultrasound. Sci. Rep 7(40650):1-8

20. Gogate PR (2011) Theory of cavitation and design aspects of cavitational reactors. In: Pankaj, Ashokkuma M (eds) Theoretical and experimental sonochemistry involving inorganic systems, 1 st edn. Springer Netherlands, Berlin, pp 31-67

21. Xu H, Zeiger BW, Suslick KS (2013) Sonochemical synthesis of nanomaterials. Chem Soc Rev 42:2555-2567

22. Agarwal A, Ng WJ, Liu Y (2011) Principle and applications of microbubble and nanobubble technology for water treatment. Chemosphere 4:1175-1180

23. Suslick KS, McNamara WB, Didenko Y (1999) Hot spot conditions during multi-bubble cavitation. In: Crum LA, Mason TJ, Reisse J, Suslick KS (eds) Sonochemistry and sonoluminescence, 1st edn. Springer Netherlands, The Netherlands, pp 191-204

24. Colmenares JC (2014) Sonication-induced pathways in the synthesis of light-active catalysts for photocatalytic oxidation of organic contaminants. Chemsuschem 7:1512-1527 
25. Suslick KS (1997) Sonoluminescence and sonochemistry. In: IEEE Ultrason. Symp. Proceedings. An Int. Symp. (Cat. No.97CH36118) 1. doi:10.1109/ULTSYM.1997.663076

26. Hagenson LC, Doraiswamy LK (1998) Comparison of the effects of ultrasound and mechanical agitation on a reacting solid-liquid system. Chem Eng Sci 53:131-148

27. Hickel S (2013) DNS and LES of two-phase flows with cavitation. Direct and Large-Eddy Simulation IX 1st edn, Springer International Publishing, Dresden, Germany, pp 1-28

28. Lorimer JP, Mason TJ (1987) Sonochemistry. Part 1-The physical aspects. Chem Soc Rev 16:239-274

29. Price G (1997) Sonochemistry and sonoluminescence. Sonochem, Ultrason. doi:10.1016/S13504177(97)85630-1

30. Mason TJ (1997) Ultrasound in synthetic organic chemistry. Chem Soc Rev 26:443-451

31. Cella R (2012) Ultrasound in synthetic applications and organic chemistry. In: Chen D, Sharma SK, Mudhoo A (ed) Handbook on applications of ultrasound: sonochemistry for sustainability, 1st edn. Taylor \& Francis Group LLC, Boca Raton, FL, p 263-277

32. Cella R, Stefani H (2009) Ultrasound in heterocycles chemistry. Tetrahedron 65:2619-2641

33. Hussein EM, Khairou KS (2014) Sonochemistry: synthesis of bioactive heterocycles. Rev J Chem 4:221-251

34. Suslick KS (2001) Encyclopedia of physical science and technology. In: Meyers RA (ed) Sonoluminescence and sonochemistry, 3rd edn. Elsevier Science Ltd, Massachusetts, pp 1-20

35. Suslick KS (2005) Sonochemistry. Van Nostrand's encyclopedia of chemistry. John Wiley \& Sons. Doi: $10.1002 / 0471740039 . v e c 2346$

36. Luo J, Fang Z, Smith RL (2014) Ultrasound-enhanced conversion of biomass to biofuels. Prog Energy Combust Sci 41:56-93

37. Gogate PR, Sutkar VS, Pandit AB (2011) Sonochemical reactors: important design and scale up considerations with a special emphasis on heterogeneous systems. Chem Eng J 166:1066-1082

38. Sutkar VS, Gogate PR (2009) Design aspects of sonochemical reactors: techniques for understanding cavitational activity distribution and effect of operating parameters. Chem Eng J 155:26-36

39. Flannigan DJ, Suslick KS (2005) Plasma formation and temperature measurement during singlebubble cavitation. Nature 434:52-55

40. Gogate PR, Pandit AB (2015) Design and scale-up of sonochemical reactors for food processing and other applications. In: Graff KF, Gallego-Juárez JA (eds) Power ultrasonics, Elsevier Ltd, Kidlington, UK, pp 725-755

41. Gogate PR, Pandit AB (2011) Cavitation Generation and usage without ultrasound: hydrodynamic cavitation. In: Pankaj, Ashokkuma M (eds) Theoretical and experimental sonochemistry involving inorganic systems, Springer, Netherlands, Berlin, pp 69-106

42. Kardos N, Luche JL (2001) Sonochemistry of carbohydrate compounds. Carbohydr Res 332:115-131

43. Thompson L, Doraiswamy L (1999) Sonochemistry: science and engineering. Ind Eng Chem Res 38:1215-1249

44. Saito S (2015) Ultrasound field and bubles. In: Grieser F, Choi PK, Enomoto N, Harada H, Okitsu K, Yasu K (eds) Sonochemistry and the acoustic bubble, 1st edn. Elsevier, Amsterdam, pp 11-39

45. Dong YY, Li SM, Ma MG, Zhao JJ, Sun RC, Wang SP (2014) Environmentally-friendly sonochemistry synthesis of hybrids from lignocelluloses and silver. Carbohydr Polym 102:445-452

46. Chatel G, Novikova L, Petit S (2016) How efficiently combine sonochemistry and clay science? Appl Clay Sci 119:193-201

47. Baig RBN, Varma RS (2012) Alternative energy input: mechanochemical, microwave and ultrasound-assisted organic synthesis. Chem Soc Rev 41:1559-1584

48. Cravotto G, Cintas P (2006) Power ultrasound in organic synthesis: moving cavitational chemistry from academia to innovative and large-scale applications. Chem Soc Rev 35:180-196

49. Luche JL (2013) Synthetic organic sonochemistry, 1st edn. Springer, US, New-York, pp 246-250

50. Piiskop S, Hagu H, Jarv J, Salmar S, Tuulmets A (2007) Sonification effects on ester hydrolysis in alcohol-water mixtures. Proc Est Acad Sci Chem 56:196-206

51. Javed T, Mason TJ, Phull SS, Baker NR, Robertson A (1995) Influence of ultrasound on the DielsAlder cyclization reaction: synthesis of some hydroquinone derivatives and lonapalene, an antipsoriatic agent. Ultrason Sonochem 2:S3-S4

52. Wang Y, Pan Y, Zhang Z, Sun R, Fang X, Yu D (2012) Combination use of ultrasound irradiation and ionic liquid in enzymatic isomerization of glucose to fructose. Process Biochem 47:976-982

53. Hofmann J, Freier U, Wecks M (2003) Ultrasound promoted C-alkylation of benzyl cyanide - Effect of reactor and ultrasound parameters. Ultrason Sonochem 10:271-275 
54. Grönroos A, Aittokallio N, Kolehmainen E (2004) Ultrasound accelerated esterification of bile acids. Ultrason Sonochem 11:161-165

55. Paulusse JMJ, Sijbesma RP (2006) Ultrasound in polymer chemistry: revival of an established technique. J Polym Sci Part A Polym Chem 44:5445-5452

56. Gawande MB, Bonifácio VDB, Luque R, Branco PS, Varma RS (2014) Solvent-free and catalystsfree chemistry: a benign pathway to sustainability. Chemsuschem 7:24-44

57. Ince NH, Ziylan A (2015) Single and hybrid applications of ultrasound for decolorization and degradation of textile dye residuals in water. In: Sharma SK (ed) Green chemistry for dyes removal from waste water, Wiley, Hoboken, NJ, USA, pp 261-263

58. Suslick K, Skrabalak S (2008) Sonocatalysis. In: Ertl G, Knozinger H, Schuth F, Weitkamp J (eds) Handbook of heterogeneous catalysis, 2nd edn. Wiley-VCH, Weinheim, pp 2006-2017

59. Bonrath W (2005) Ultrasound supported catalysis. Ultrason Sonochem 12:103-106

60. Yunus R, Salleh SF, Abdullah N, Biak DRA (2010) Effect of ultrasonic pre-treatment on low temperature acid hydrolysis of oil palm empty fruit bunch. Bioresour Technol 101:9792-9796

61. Choi J, Kim S (1994) Effect of ultrasound on sulfuric acid-catalysed hydrolysis of starch. Korean J Chem Eng 11:178-184

62. Yachmenev G, Condon BD, Lambert AH (2007) Intensification of enzymatic reactions in heterogeneous systems by low intensity, uniform sonication: new oad to "Green Chemistry". In: Eggleston G, Vercellotti JR (eds) Industrial application of enzymes on carbohydrate-based materials, 1 st edn. American Chemical Society, Washington, pp 137-156

63. Yang F, Li L, Li Q, Tan W, Liu W, Xian M (2010) Enhancement of enzymatic in situ saccharification of cellulose in aqueous-ionic liquid media by ultrasonic intensification. Carbohydr Polym $81: 311-316$

64. Ninomiya K, Ohta A, Omote S, Ogino C, Takahashi K, Shimizu N (2013) Combined use of completely bio-derived cholinium ionic liquids and ultrasound irradiation for the pretreatment of lignocellulosic material to enhance enzymatic saccharification. Chem Eng J 215-216:811-818

65. Chatel G, Rogers RD (2014) Review: oxidation of lignin using ionic liquids-an innovative strategy to produce renewable chemicals. ACS Sustain Chem Eng 2:322-339

66. Finch KBH, Richards RM, Richel A, Medvedovici AV, Gheorghe NG, Verziu M, Coman SM, Parvulescu VI (2012) Catalytic hydroprocessing of lignin under thermal and ultrasound conditions. Catal Today 196:3-10

67. Napoly F, Kardos N, Jean-Gérard L, Goux-Henry C, Andrioletti B, Draye M (2015) H2O2-mediated kraft lignin oxidation with readily available metal salts: what about the effect of ultrasound? Ind Eng Chem Res 54:6046-6051

68. Taghizadeh MT, Seifi-Aghjekohal P (2015) Sonocatalytic degradation of 2-Hydroxyethyl Cellulose in the presence of some nanoparticles. Ultrason Sonochem 26:265-272

69. Taghizadeh MT, Abdollahi R (2011) Sonolytic, sonocatalytic and sonophotocatalytic degradation of chitosan in the presence of TiO2 nanoparticles. Ultrason Sonochem 18:149-157

70. Behling R, Chatel G, Valange S (2017) Sonochemical oxidation of vanillyl alcohol to vanillin in the presence of a cobalt oxide catalyst under mild conditions. Ultrason Sonochem 36:27-35

71. Li G, Li L, Liu L, Lai Y, Li W, Kong H (2012) Study on preparation of levulinic acid by hydrolysis of glucose using ultrasound-microwave assisted hydrochloric acid. Chem Bioeng 2012:5-7

72. Zhou K, Qian H, Zhoun H, Zhu K (2008) Study on technology of ultrasound-microwave assisted generates levulinic acid by hydrolysis of corn starch. Sci Technol Food Ind 29:243-246

73. Naik R, Nizam A, Siddekha A, Pasha MA (2011) An efficient sonochemical oxidation of benzyl alcohols into benzaldehydes by $\mathrm{FeCl} 3 / \mathrm{HNO} 3$ in acetone. Ultrason Sonochem 18:1124-1127

74. Qin ZYY, Tong GLL, Chin YCF, Zhou JCC, Frank Chin YC, Zhou JCC (2011) Preparation of ultrasonic-assisted high carboxylate content cellulose nanocrystals by tempo oxidation. BioResources 6:1136-1146

75. Brochette-Lemoine S, Trombotto S, Joannard D, Descotes G, Bouchu A, Queneau Y (2000) Ultrasound in carbohydrate chemistry: sonophysical glucose oligomerisation and sonocatalysed sucrose oxidation. Ultrason Sonochem 7:157-161

76. Lemoine S, Thomazeau C, Joannard D, Trombotto S, Descotes G, Bouchu A, Queneau Y (2000) Sucrose tricarboxylate by sonocatalysed TEMPO-mediated oxidation. Carbohydr Res 326:176-184

77. Paquin M, Loranger É, Hannaux V, Chabot B, Daneault C (2013) The use of Weissler method for scale-up a Kraft pulp oxidation by TEMPO-mediated system from a batch mode to a continuous flow-through sonoreactor. Ultrason Sonochem 20:103-108 
78. Rinsant D, Chatel G, Jérôme F (2014) Efficient and selective oxidation of D-Glucose into Gluconic acid under low-frequency ultrasonic irradiation. Chem Cat Chem 6:3355-3559

79. Bujak P, Bartczak P, Polanski J (2012) Highly efficient room-temperature oxidation of cyclohexene and D-glucose over nanogold $\mathrm{Au} / \mathrm{SiO} 2$ in water. J Catal 295:15-21

80. Toukoniitty B, Kuusisto J, Mikkola J, Salmi T, Murzin DY (2005) Effect of ultrasound on catalytic hydrogenation of D-Fructose to D-Mannitol. Ind Eng Chem Res 44:9370-9375

81. Ninomiya K, Takamatsu H, Onishi A, Takahashi K, Shimizu N (2013) Ultrason Sonochem 20:1092-1097

82. Penconi M, Rossi F, Ortica F, Elisei F, Gentili PL (2015) Hydrogen Production from Water by Photolysis, Sonolysis and Sonophotolysis with Solid Solutions of Rare Earth, Gallium and Indium Oxides as Heterogeneous Catalysts. Sustainability 7:9310-9325

83. Jafari O, Zilouei H (2016) Enhanced biohydrogen and subsequent biomethane production from sugarcane bagasse using nano-titanium dioxide pretreatment. Bioresour Technol 214:670-678 